\title{
OS QUÍMICOS OCULTOS E SUA EXTRAORDINÁRIA JORNADA AO MUNDO DOS ÁTOMOS
}

\author{
Lediany Forostecki e Ourides Santin Filho* \\ Departamento de Química, Centro de Ciências Exatas, Universidade Estadual de Maringá, Av. Colombo, 5790, 87020-900 Maringá \\ - PR, Brasil
}

Recebido em 26/03/2013; aceito em 14/06/2013; publicado na web em 02/08/2013

\begin{abstract}
THE OCCULT CHEMISTS AND THEIR EXTRAORDINARY JOURNEY INTO THE WORLD OF ATOMS. At the end of the XIX century, a group of chemists and theosophists called the Occult Chemists suggested it would be possible "to see" atoms by clairvoyance. In a meditative situation, a skilled person in contact with a substance would thus be able to see magnified atoms and molecules, as well as its internal structure. Annie Besant was the leader of this group and, together with Curuppumullage Jinarajadasa, Charles Leadbeater and Bertram Keightley, they devised an extraordinary atomic theory in which atoms consisted of smaller, indivisible units of energy called anu. In this paper, we present the fundamental principles of this unusual theory.
\end{abstract}

Keywords: Annie Besant; occult chemists; atomic structure.

\section{INTRODUÇÃO}

A busca pela compreensão da estrutura da matéria em geral, e do átomo em particular é, sem dúvida, responsável por episódios valiosos na história da Química. Várias concepções surgiram sobre o conceito de átomo, em circunstâncias, culturas e épocas diferentes. As especulações envolvem a participação de muitos pensadores e constituem uma história que não pertence somente à Química, mas é um tema que gera múltiplos debates em filosofia, teologia, física e outras áreas.

No Ocidente, o debate acerca da natureza discreta da matéria foi iniciado pelos filósofos gregos, centenas de anos antes da era cristã, sendo posteriormente explorado sob diversos aspectos pelos mecanicistas dos séculos XVII e XVIII, vindo a se estabelecer na linguagem científica moderna somente na passagem do século XIX para o século XX. ${ }^{1}$

Os primeiros atomistas parecem, com poucas exceções, ter desenhando um quadro no qual os átomos seriam pequenos, massivos e rígidos. Isaac Newton (1643-1727), em sua obra Opticks é bastante explícito ao afirmar que "parece provável a mim que Deus criou, no início, a matéria como partículas móveis de natureza sólida, massiva, dura e impenetrável". ${ }^{2}$

Para Walter Charleton (1620-1707), o universo seria constituído por átomos e vacuidades, sendo aqueles minúsculas e incorruptíveis partículas, constituídas por um único tipo de matéria, mas diferentes entre si quanto ao tamanho, forma e peso. Seu modelo era herança dos epicuristas. ${ }^{3}$ Por outro lado, Roger Joseph Boscovich (1711-1787), via os átomos como "centros de força", pontos massivos mas sem extensão, sujeitos a forças de natureza gravitacional. ${ }^{4}$

Do final do século XIX ao primeiro quarto do século XX houve intenso debate e muitas tentativas da comunidade científica de consolidar as explicações sobre a estrutura da matéria. A atividade dos físicos e dos químicos foi tão intensa naquele período que se torna difícil dar conta da simultaneidade das teorias e trabalhos que tiveram influência direta sobre a formação da teoria atômica. Modelos proliferavam em diversos cantos do mundo científico.

William Prout (1785-1850) propunha, por exemplo, que os átomos fossem constituídos por agregados de diferentes quantidades e configurações de átomos de hidrogênio. ${ }^{5}$ Tal ideia se consolidou

*e-mail: osantin@uem.br numa hipótese, defendida por William Crookes (1832-1919), de que os átomos seriam constituídos por uma partícula última, o "protilo". ${ }^{6}$

A teoria de John Dalton (1766-1844), originada de seus estudos acerca da atmosfera, sugeria a existência de partículas fundamentais, minutas e indivisíveis, circundadas por uma nuvem de calórico. Ela se rivalizava com teorias do éter físico, tal como sugerido por Lorde Kelvin (William Thomson, 1824-1907), de que o átomo seria simplesmente um vortex no fluido etéreo. ${ }^{4}$

A noção de que a matéria é constituída por átomos pressupõe que eles têm massa, e determinar com precisão aceitável o valor das massas atômicas de cada elemento conhecido torna-se uma noção incontornável e indispensável a todos os químicos. ${ }^{7}$

Numa análise detalhada da atmosfera científica da época, fenômenos novos ${ }^{8}$ surgem nos laboratórios dos físicos e químicos: raios catódicos são estudados pelo inglês William Crookes (1832-1919); raios X são detectados ${ }^{9}$ pelo alemão Wilhelm C. Röntgen (18451923); Henri Becquerel (1852-1908) observa a radioatividade em sais de urânio, enquanto Joseph J. Thomson (1856-1940) identifica uma partícula elementar de carga elétrica negativa mediante seus estudos com raios catódicos. O elétron se constituiu na primeira partícula menor do que o átomo que foi efetivamente detectada. ${ }^{10}$

No ano de 1898, Rutherford (1871-1937) detecta partículas radioativas enquanto Marie Curie (1867-1934) refere-se à radioatividade como uma propriedade atômica. ${ }^{11}$

A matéria parecia aos poucos revelar seus segredos e a busca por sua estrutura empolgou não apenas físicos e químicos, mas filósofos e outros pensadores. É neste contexto que encontramos também algumas investigações que empregavam métodos experimentais nada ortodoxos para a Ciência convencional, praticada nos laboratórios da época. Referimo-nos especialmente aos que foram apresentadas por um grupo de teósofos, especialmente por uma brilhante integrante desse grupo, pesquisadora que possuía enorme interesse pela Química, mas que também se preocupava com causas sociais, políticas e religiosas.

Essa história curiosa teve início em 1895. Sua protagonista, Annie Besant, reuniu-se com seus colegas no Surrey, condado situado na região sul da Inglaterra, para iniciar uma investigação sobre a estrutura da matéria por meio da observação direta dos átomos. O grupo era composto pelos principais membros da Sociedade Teosófica, o indiano Curuppumullage Jinarajadasa e os ingleses Charles Leadbeater e Bertram Keightley. Todos acreditavam que, num estado meditativo, 
poderiam visitar o interior dos átomos, como numa viagem de descoberta, na qual a percepção visual do observador poderia ser amplificada a ponto de objetos em escala microscópica aparecerem a eles como grandes e, assim, possíveis de serem observados e registrados. ${ }^{12,13}$

Apresentaremos neste artigo um pouco da vida de Annie Besant e as principais características do seu incrível modelo atômico, completamente estranho à comunidade científica, e publicado na obra Occult Chemistry, com ajuda de Charles Leadbeater. Esse curioso grupo de pesquisadores ficou conhecido como os "Químicos Ocultistas".

\section{A VIDA DE ANNIE BESANT}

Annie Woods nasceu em Londres em 1 de outubro de 1847 Vinda de uma família de irlandeses, foi educada unicamente por Ellen Marryat, irmã do romancista inglês capitão Frederick Marryat, autor da obra Midshipman Easy, best-seller infantil muito popular na época. Durante sua adolescência, Annie tornou-se intensamente religiosa e, em 1867, casou-se com o reverendo Frank Besant, vigário em Sibsey, Lincolnshire. Porém, mesmo com o nascimento dos filhos Digby e Mabel, o casamento de Mme. Besant, bem como suas crenças religiosas, acabaram. Após deixar o marido em 1872, Annie Besant voltou para Londres para morar com a mãe e começou a preocupar-se com questões sociais, assumindo aos poucos seu ateísmo. Em 1874 ela reuniu-se com o ateísta e ativista político Charles Bradlaugh, e juntou-se à National Secular Society, organização dedicada a expor o que consideravam as falácias das religiões e da crença cristã em particular. Foi neste ambiente que acabou tornando-se uma oradora talentosa e, por ser uma grande defensora dos direitos das mulheres, passou a escrever artigos para o jornal do grupo. Iniciou então sua carreira de jornalista junto ao National Reformer, revista editada pela Secular Society, com publicações que lhe renderam grande notoriedade mas também muitas críticas em todo o Reino Unido.

Em seguida, foi estudar licenciatura em ciências na Universidade de Londres, que havia recentemente decidido admitir estudantes mulheres. Para sua instrução, procurou por Edward Aveling, professor de ciência do King's College de Londres. Tal foi o calor dessa amizade que Aveling rapidamente aderiu às fileiras dos docentes da National Secular Society, para ministrar cursos de Química e Fisiologia Animal. Sua assistente nestas ocasiões foi Annie Besant.

Entretanto, seu ateísmo começou a lhe prejudicar. Recebeu notas baixas em química avançada e lhe foi negado acesso ao Royal Botanical Gardens, em Regent's Park, o que a impediu de prosseguir seu trabalho de botânica. O pretexto era de que seu ateísmo poderia corromper outras pessoas. Teve também recusada sua entrada em uma aula prática de botânica do University College de Londres, por motivos religiosos. Perto da chegada de sua formatura, por três vezes realizou seu exame de química prática e em todos eles foi reprovada. O motivo teria sido um examinador que lhe disse de antemão que não poderia aprová-la por causa de seu ateísmo. Por esta razão, Annie nunca obteve seu diploma.

Em 1885, ela aderiu a um movimento socialista britânico, o Fabian Society, e logo tornou-se uma oradora e conferencista renomada. Naquele ano conheceu o escritor George Bernard Shaw, com o qual compartilhou seu tempo e trabalho na propaganda do ideal socialista. Em 1889, Annie colaborou com a organização de uma greve de meninas que trabalhavam em uma fábrica de fósforos, a Bryant \& May, então uma das indústrias mais poderosas da época e que, como muitas outras, oferecia condições de trabalho desumanas, em que havia inalação de fósforo pelas operárias, com graves efeitos sobre a saúde, incluindo a perda dos dentes. Estes motivos levaram Annie a mobilizar e formar a União das Operárias, uma poderosa instituição feminina da Inglaterra que lutou pela melhoria das condições de trabalho. Em meio a uma variedade de atividades, as causas sociais foram as principais responsáveis pela surpreendente reviravolta na vida de Annie. ${ }^{12,14}$

\section{A SOCIEDADE TEOSÓFICA}

A Teosofia é um sistema de filosofia e crença religiosa preocupada com a natureza dos processos divinos e suas relações com o universo dos fenômenos. Em sua forma mais moderna, a Sociedade Teosófica foi fundada em 1875, nos círculos espiritualistas de Nova Iorque, por Helena Petrovna Blavatski, pelo Coronel Olcott e por W. Q. Judge.

A Teosofia logo se tornou muito popular na Grã Bretanha e no continente europeu, nos anos de 1880. Seus vários sistemas de crenças, incluindo a reencarnação, adquiriram grande notoriedade, principalmente pela tentativa de unir religião com racionalismo científico. As arrojadas e novas ideias da Sociedade Teosófica eram influenciadas pelas antigas filosofias orientais, tradições ocultas antigas, incluindo a filosofia de Pitágoras.

Em 1888 Madame Blavatsky (1831-1891) publicou sua principal obra, A Doutrina Secreta, que viria a tornar-se o livro mais importante para os teosofistas. Foi quando W. T. Stead, editor da Pall-Mall Gazette, tendo em mãos o trabalho, foi pedir para que Annie Besant fizesse a revisão da obra. Ao entrar em contato com os conhecimentos de Madame Blavatsky, esta imediatamente converteu-se para a Teosofia, permanecendo adepta até o fim de sua vida. A Sociedade Teosófica mal podia acreditar em sua sorte de adquirir uma brilhante oradora e jornalista. Contudo, parece que Annie Besant, estudiosa em química, viu na teosofia uma forma mais alta de ciência, um meio pelo qual fenômenos naturais e visões ainda não disponíveis para as ciências físicas pudessem ser revelados. Acreditando ser a Teosofia necessária para a complementação da ciência, Annie passou então a dedicar-se a promoção da causa teosófica. ${ }^{12,15}$

Besant foi incansável em sua preocupação pelo bem-estar da nascente sociedade de intelectuais. Ela residiu por longos períodos em Adyar, na Índia, e viajou extensivamente pela Europa, Estados Unidos e Austrália, tendo exercido considerável influência sobre Jawaharlal Nehru, líder socialista que foi primeiro-ministro da Índia durante muitos anos e que era, naquele período, membro da Sociedade Teosófica.

A energia de Annie parecia ser infinita. Em julho de 1898 ajudou a fundar, em Benares, o Central Hindu College, um colégio só para hindus, com base nas suas tradições e cultura. Em seus esforços para a divulgação da Teosofia, tornou-se Chefe Escoteira Comissária para a Índia. Posteriormente, apresentou ao mundo um garoto indiano chamado Jiddu Krishnamurti, que apoiou a causa do Estado de origem indiana e acabou tornando-se presidente do Congresso Nacional Indiano. Mas o patrocínio de Krishnamurti terminou quando este renunciou às suas pretensões, e o grupo perdeu a liderança do movimento hindu para Mahatma Gandhi. ${ }^{16}$

Besant faleceu em 20 de setembro de 1933, e sua influência entrou em declínio, embora mantivesse a presidência da Sociedade Teosófica até o fim. A memória duradoura do grande interesse de Annie Besant pela estrutura da matéria está ricamente impressa na obra Occult Chemistry, e suas várias edições, algumas das quais aqui faremos uma breve apresentação, publicada com seu inseparável amigo Charles Leadbeater, ficando clara a sua vontade de contribuir com a teosofia em todos os ramos do conhecimento humano.

\section{O MÉTODO DE INVESTIGAÇÃO E OS MODELOS ATÔMICOS}

Em suas duas primeiras décadas de existência, a Teosofia procurou legitimar-se como ciência válida e os teosofistas procuraram dar-lhe uma roupagem similar à ciência 'oficial', acompanhando de 
perto os trabalhos de físicos e químicos de destaque (William Crookes, William Ramsay, Conrad Roentgen, J. J. Thomson, Frederick Soddy, Ernest Rutherford e o casal Curie). Os teosofistas acreditavam que seus resultados teóricos e experimentais validavam as teorias medievais da alquimia, dentre elas a milenar noção de que a matéria seria constituída por uma prima materia. ${ }^{17}$

Explicar o excêntrico modelo apresentado pelos químicos ocultos não é tarefa fácil, visto que a linguagem utilizada em suas publicações é um tanto confusa e obscura. Seus textos são profusamente ricos em termos e conhecimentos oriundos das antigas escrituras orientais, de significado desconhecido para os não iniciados e, além de tudo, há utilização imprecisa ou diferente de alguns conceitos e linguagem aceitos pela comunidade científica tais como átomos, moléculas, eletropositividade, eletronegatividade, etc. Contudo, é importante lembrar que este modelo foi apresentado ao final do século XIX, momento em que até mesmo a ciência oficial passava por uma crise em relação à aceitação e o consenso sobre alguns termos e conceitos utilizados na linguagem científica, sobretudo no que diz respeito à teoria atômica.

Cientes das novas e importantes descobertas da Ciência, os Teosofistas elaboraram sua proposta como uma tentativa de reaproximar a ciência fortemente materialista e mecanicista daquele período com uma espiritualidade cada vez mais relegada a segundo plano. O maior símbolo desse materialismo se traduzia no uso dos novos instrumentos que conduziram físicos e químicos às descobertas já citadas. Espectroscópios, tubos de raios catódicos, eletrômetros, câmeras de bolhas e de ionização eram alguns dos fortes dispositivos paradigmáticos adotados na defesa do "método científico" vigente. Em parceria a eles, os Químicos Ocultos ofereciam um modo de percepção "mais humanizado" da matéria

As the new atomic science, through ever more sophisticated detectors opened a realm that could not be directly perceived by the physical senses, occult chemistry offered an alternative, a mode of scientific experimentation that could attempt to claim legitimacy through its scientific writing, charts and visual illustrations of data while it also connected the human psyche to the subatomic world through a direct form of perception - that is, clairvoyance (Morrison, M., 2007, p. 69). ${ }^{18}$

A Sociedade Teosófica procurava também se legitimar por meio de um intenso trabalho de propaganda. Seus encontros, longe de serem secretos, como os de outras sociedades herméticas, eram abertos ao público e os Teósofos procuravam divulgar extensivamente suas ideias. Em 1887 Madame Blavatsky fundou a revista Lucifer, veículo de divulgação do grupo. Besant juntou-se à ela como co-editora em 1890 e, em 1891, a revista mudou de nome para The Theosophical Review. Já naquele ano Besant ampliou seu engajamento à "ciência oficial" por meio da publicação sistemática na revista da coluna "On The Watch-Tower", dedicada a ser um fórum de discussão de notícias e artigos sobre a nova física que emergia dos laboratórios. A revista viria a publicar os primeiros registros diretos de observações de átomos (hidrogênio, oxigênio, nitrogênio, bem como o occultum) em 1895.

As investigações atômicas de Besant e Leadbeater estão compiladas na obra Occult Chemistry, com edições em 1909, 1919 e 1951, e subsequentes reimpressões, até hoje disponíveis no mercado.

Exploramos aqui três publicações ${ }^{19,20,21}$ da Occult Chemistry, que apresentam algumas discrepâncias entre si, inclusive nos aspectos de classificação dos átomos em grupos segundo suas formas geométricas predominantes. Procuramos aqui extrair o que havia de comum e pitoresco em seus textos.

Publicado em 1909, a obra Occult Chemistry: a series of clairvoyant observations on the chemical elements ${ }^{19}$ apresenta imagens da estrutura atômica de muitos elementos químicos que, segundo seus autores, foram obtidas por clarividência, método ocultista de investigação.

Para os Químicos Ocultos, usando de clarividência, uma pessoa treinada seria capaz de "ver" mais claramente objetos, imagens e sons não perceptíveis pelos sentidos comuns, ou seja, através de um estado meditativo, o indivíduo poderia registrar suas impressões mentais, da mesma maneira que um cientista registra imagens que obtém de um microscópio.

Annie Besant, supostamente detentora da citada habilidade clarividente, e igualmente envolvida com química durante o período de 1878-1883, resolve utilizar seus conhecimentos para solucionar o mistério da estrutura atômica. Contudo, segundo ela própria, para fazer essa viagem pelo interior dos átomos, seria preciso estar na presença do material a ser investigado. Parte da dificuldade de se dispor de substâncias químicas foi solucionada por seus amigos, também clarividentes, Charles Leadbeater, e o jovem indiano e hábil desenhista C. Jinarajadasa, autor das imagens aqui apresentadas.

As primeiras investigações acerca da estrutura da matéria foram feitas na Inglaterra em 1895, ano em que Wilson construiu sua primeira câmara de bolhas ${ }^{22}$ e que Roentgen descobriu os raios $\mathrm{X}^{9}$ e os primeiros átomos observados foram os dos gases hidrogênio, oxigênio e nitrogênio, mais um quarto gás que, segundo os pesquisadores ocultistas, ainda não havia sido reconhecido pela ciência oficial. A este elemento os autores deram o nome de Occultum (imagens deste e de outros átomos e 'moléculas' estão no material suplementar). As descrições detalhadas da estrutura interna destes átomos foram publicadas em Londres na revista Lucifer, na edição de novembro de 1895.

Explicam os químicos ocultos que os átomos não ostentam um rótulo que permita, uma vez visualizados, a atribuição imediata a seus elementos químicos, e que sua estrutura é constituída de unidades menores denominadas 'átomos físicos últimos' (ultimate physical atoms), termo que depois foi substituído por anu,

The atoms do not carry their own labels and the first problem was that of identification. [...] But it was only after the fullest examination of the constituent parts of each gas (for each socalled "atom", the un-cut-able", was found to be composed of smaller units) that finally was achieved regarding the identity of the gases. [...] Each such unit was then called an "ultimate physical atom". Some thirty years later it seemed simpler to use the Sanskrit term for this ultimate particle of matter; the word is "Anu", pronounced as in Italian, or in English as "ahnoo". The word Anu does not add "s" to make the plural but remains unchanged. (Leadbeater e Besant, 1950, p.1). ${ }^{20}$

A escolha dos teósofos por este termo provém da influência de algumas filosofias orientais do século VI a.C. A palavra anu, designa, em sânscrito, a partícula elementar indivisível da matéria. O termo é encontrado em escrituras das antigas religiões da Índia, como o jainismo e o hinduísmo. O que determinava, portanto, o reconhecimento do elemento químico e seu peso atômico (que em linguagem moderna é definido pela massa atômica), seria a contagem do número de átomos físicos últimos observados, ou seja, sua quantidade de anu. Curiosamente, os Ocultistas já reconheciam plenamente que os átomos seriam constituídos por entidades menores, discussão ainda em aberto na comunidade científica da época. Lembremos que as primeiras observações dos ocultistas datam de 1895 e que o elétron, primeira partícula subatômica reconhecida, foi observada somente em 1897.

Os anu de Besant eram os equivalentes espirituais das partículas mecânicas últimas, do átomo de hidrogênio no modelo de Prout, dos vortex de Kelvin e do "protilo" de Crookes e estes anu seriam, 
para os teosofistas, confirmações da hipótese da prima materia dos alquimistas.

Em sua identificação, o hidrogênio revelou-se constituído por 18 unidades de $a n u$, o nitrogênio por 261 , o oxigênio por 290 e o quarto gás, o occultum, por 54 dessas unidades. O hidrogênio, por possuir menor quantidade de átomos unitários, foi escolhido para ser o elemento padrão e para ele foi atribuído peso atômico 1 (um). Valendo-se disso, o número de unidades do oxigênio e do nitrogênio foi dividido por 18, resultando dessa divisão os pesos atômicos do nitrogênio (14,5), do oxigênio (16,1) e do occultum (3). Manteremos aqui, por fidelidade histórica, a denominação de peso atômico para o que hoje chamamos de massa atômica.

Ainda nestas primeiras investigações, os ocultistas também apresentaram novos conceitos sobre a natureza física da matéria. A primeira e surpreendente revelação foi a de que esta não se apresentaria apenas em três estados físicos, como admite a ciência convencional, mas que, além de sólido, líquido e gasoso, encontraríamos outros quatro estados da matéria. Os químicos ocultistas acreditavam que estes estados seriam mais sutis que o estado gasoso e identificaram neles funções semelhantes ao éter, fluido que preencheria todo o universo de forma sutil, cuja busca mobilizava os melhores físicos da época. Aos novos estados os investigadores teosóficos denominaram estados etéricos ou, mais especificamente, estado etérico IV ou proto-elemental (E4), estado etérico III ou meta-elemental (E3), estado etérico II ou hyper-elemental (E2) e, por último, o estado etérico I (E1), que corresponderia ao "átomo último" ou anu. Estes últimos quatro estados só poderiam ser verificados mediante a "desintegração" ou "dissociação" (não no sentido moderno dos termos) dos átomos, alcançável até então somente com o auxílio da clarividência.

Segundo os ocultistas, ao isolarmos por clarividência um átomo de um elemento químico no seu estado gasoso e o dividirmos sucessivamente em seus estados mais íntimos, chegaremos à "partícula última”, constituída por matéria astral, ou etérica, e não mais física.

As the words "ultimate physical atom" must frequently occur, it is necessary to state what we mean by the phrase. Any gaseous chemical atom may be dissociated into less complicated bodies; these, again, into still less complicated; these, again, into yet still less complicated. These will be dealt with presently. After the third dissociation but one more is possible; the fourth dissociation gives the ultimate physical atom. This may vanish from de physical plane, but it can undergo no further dissociation on it (Leadbeater $e$ Besant, 1919, p.22). ${ }^{19}$

Valendo-se disso, ao chegar ao quarto e último estado, seria possível verificar que os elementos químicos são formados por "átomos últimos" a já citada partícula $a n u$.

Os esquemas das descrições detalhadas da estrutura interna dos gases hidrogênio, oxigênio e nitrogênio (Figura 1) são mostrados com a representação de seus estados etéricos.

Segundo os químicos ocultos, existe uma energia que circula por estes átomos. No diagrama representado na Figura 1, a força ou direção em que circula essa energia aparece como linhas tracejadas e flechas. O anu está marcado com a letra e foi representado apenas em alguns esquemas, pois é o mesmo em todos os corpos. Os números e letras que aparecem em todos os desenhos, servem para que o leitor possa seguir corretamente a sequência das divisões destas partículas.

Dizem os ocultistas que é difícil explicar aos não iniciados a estrutura dessas imagens e como elas são obtidas. A representação seria apenas uma tentativa de aproximação da imagem real, uma vez que elas aparecem ao clarividente como em quatro dimensões,

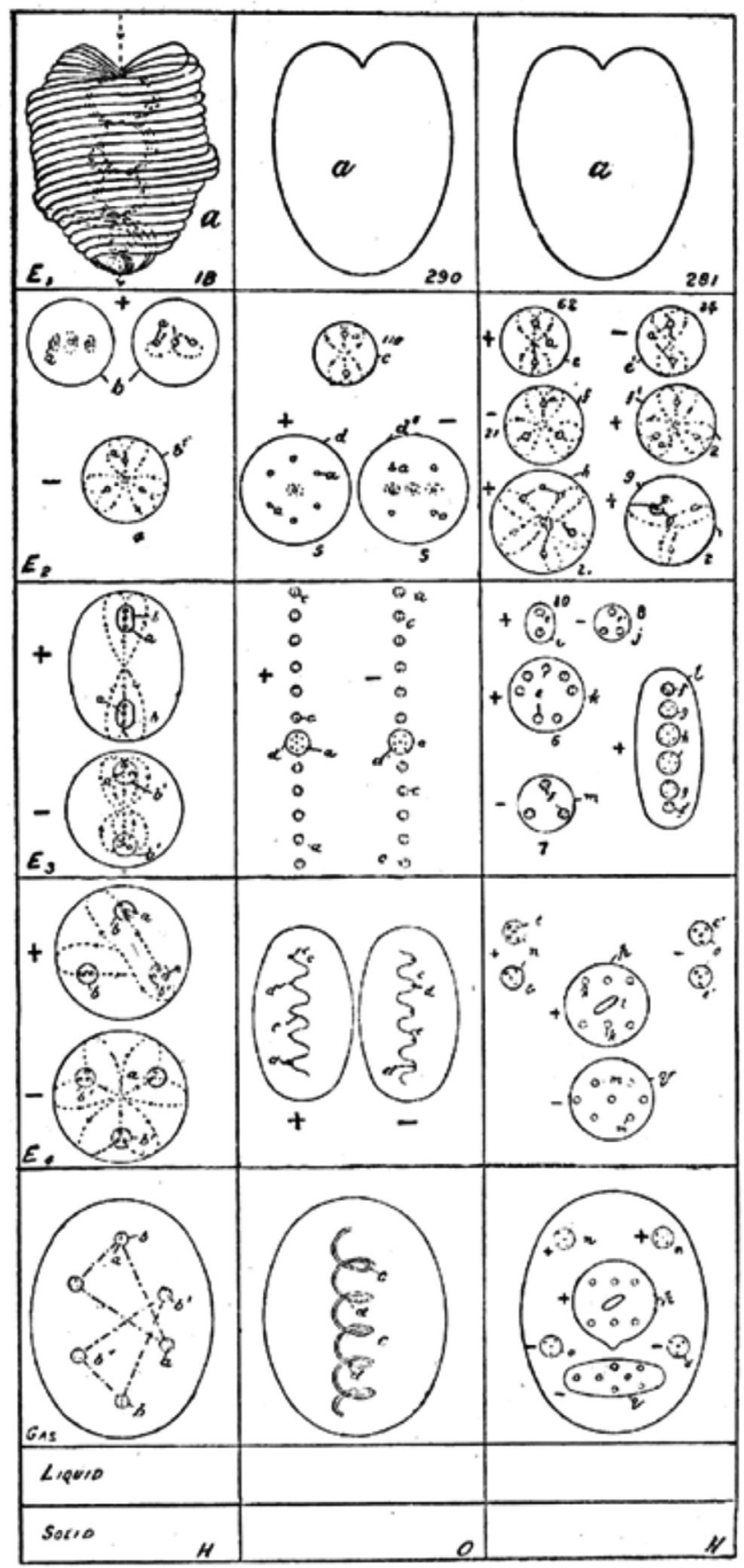

Figura 1. Os átomos dos elementos hidrogênio, nitrogênio e oxigênio e suas sucessivas subestruturas internas, até a partícula última ou апи (Besant \& Leadbeater, La Chimie Occulte)

sendo difícil passar para o papel uma imagem realista dos átomos e suas estruturas.

Ao observar o estado etérico I, os ocultistas disseram ter encontrado dois tipos de anu, um de natureza 'positiva' e outra 'negativa', ou ainda 'masculina' e 'feminina'. Constataram que tal diferença resultava de suas estruturas espirais, enroladas em direções opostas. Seria como dizer que o anu negativo era como um reflexo do anu positivo (Figura 2). De fato, eles se constituem em imagem especular um do outro.

Do que seriam constituídos, afinal, os anu? Na tentativa de apresentar um estudo minucioso desta partícula última, os ocultistas apresentaram, na primeira edição do Occult Chemistry, em 1909 um texto inédito chamado "O éter do espaço", com o objetivo de 

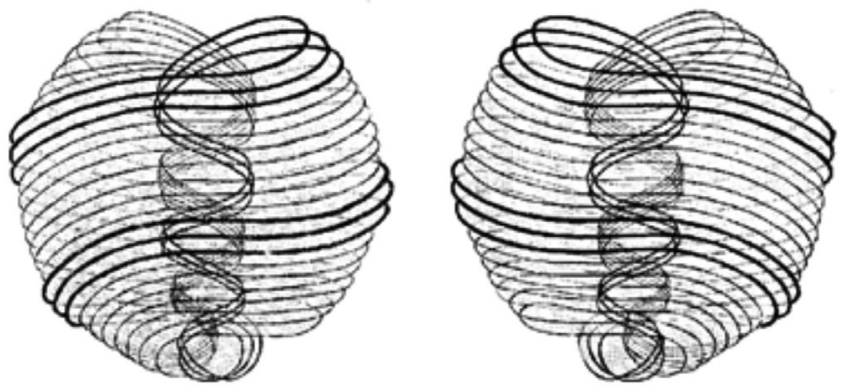

Figura 2. A partícula última seria o último ponto observado na divisão da matéria física, as duas formas são idênticas uma da outra, só se diferem como um objeto e sua imagem no espelho, e o fato de uma ser 'positiva' $e$ a outra 'negativa' ainda 'masculina' e 'feminina' (Besant \& Leadbeater, La Chimie Occulte)

esclarecer questões sobre o éter, tema que gerava muita discussão e especulações por parte dos cientistas.

O éter, que supostamente preenche todo o espaço, foi chamado pelos ocultistas de koilon, e foi interpretado de forma diferente do éter dos cientistas. Ele seria o estado último da matéria, para além dos três estados físicos aceitos, e seria o responsável pela luz, calor e eletricidade:

Theosophical investigators [...] have been able to deal with states of matter higher than the gaseous, and have observed that it is by means of vibrations of this finer matter that light, heat and electricity manifest themselves to us (Leadbeater $e$ Besant, 1950, p.16). ${ }^{20}$

O koilon, por vezes também chamado de "espaço vazio", seria uma substância que envolve todo o universo. Ele possuiria densidade muito superior à de todos os corpos conhecidos e a matéria existente não seria constituída de koilon, mas de ausência de koilon,

Let us for the moment name this substance koilon - since it fills what we are in the habit of calling empty space. [...] It answers to scientific demands in so far that it is out of all proportion denser than any substance known to us - quite infinitely denser - belonging to another order and typo of density altogether. For the very kernel and nexus of the whole conception is that what we call matter is not koilon, but the absence of koilon. So that to comprehend the real conditions we must modify our ideas of matter and space - modify them almost to the extent of reversing our terminology. Emptiness has become solidity and solidity has become emptiness (Leadbeater e Besant, 1950, p.16). (grifo nosso). ${ }^{20}$

O anu seria, assim, constituído por koilon. Em sua arquitetura, cada апи apresentaria dez anéis ou filamentos contínuos que, uma vez desenrolados, resultariam em 1680 espirais menores ainda que, por sua vez, também desenroladas, resultariam em outras tantas espirais menores (Figura 3). Conforme os próprios autores

The atom consist of ten wires, which divide themselves naturally into two groups - the three which are thicker and more prominent, and the seven thinner ones which correspond to the colours and planets. (Leadbeater e Besant, 1950, p.19). ${ }^{20}$

O processo de desagregar as espirais pode-se repetir até o ponto de que todos os filamentos estejam completamente desenrolados, resultando num anel fechado ou uma enorme "circunferência de

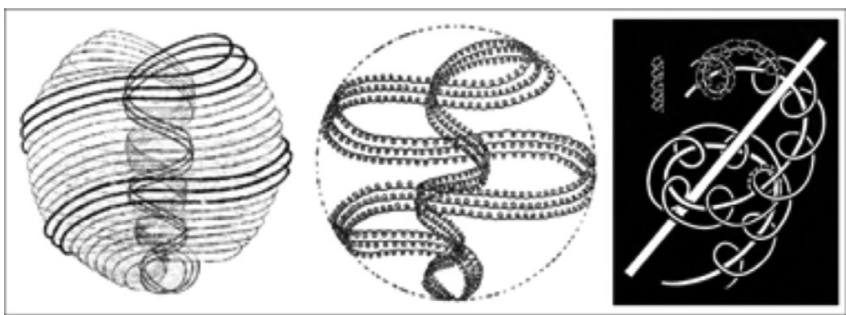

Figura 3. O апи ou "átomo físico último" é formado por filamentos que, se desagregados, resultam em filamentos menores, que por sua vez, são formados por espirais menores ainda (Besant \& Leadbeater, La Chimie Occulte)

pontos os menores que se pode imaginar", como "pérolas em um fio invisível", tal que para formar um "átomo último" são necessários milhões dessas pequenas espirais. $\mathrm{O}$ trecho reproduzido abaixo descreve a criatividade do modelo do "átomo último".

To help us to understand more clearly let us examine the ultimate atom of the physical plane. It is composed of ten rings or wires, which lie side by side, but never touch one another. If one of these wires be taken away from the atom, and as it were untwisted from its peculiar spiral shape and laid out on a flat surface, it will be seen that it is a complete circle - a tightly twisted endless coil. This coil is itself a spiral containing 1,680 turns; it can be unwound, and it will then make a much larger circle. There are in each wire seven sets of such coils or spirillae, each finer than the preceding coil, to which its axis lies at right angles. The process of unwinding them in succession may be continued until we have nothing but an enormous circle of the tiniest imaginable dots lying like pearls upon an invisible string. These dots are so unconceivable small that many millions of them are needed to make one ultimate atom. They appear to be the basis of all matter of which we at present know anything (Leadbeater e Besant, 1950, p.17). ${ }^{20}$

Voltemos um pouco aos átomos. Os registros das estruturas atômicas foram crescendo. Tornou-se fundamental ter acesso a novos materiais. Foi assim que, durante as férias de verão de 1907, em Weisser-Hirsch na Alemanha, Besant e Leadbeater foram a um museu de mineralogia próximo, na cidade de Dresden, onde Jinarajadasa pôde registrar e desenhar esquemas da estrutura atômica de muitos minerais visualizados pelos outros dois investigadores. Algumas amostras mais difíceis de serem obtidas foram solicitadas ao renomado físico Sir Willian Crookes. Ainda que Crookes não estivesse envolvido e nem interessado nas pesquisas clarividentes, ele fornecia material a Leadbeater. O total de elementos químicos examinados somava 59 (além de vários isótopos), dos 78 elementos então conhecidos, conforme uma "Lista Internacional" de pesos atômicos apresentada pelo químico alemão Otto Erdmann.

O verão daquele ano de 1907 em Weisser-Hirsch acabou sendo muito produtivo para os ocultistas. Foi nesse período que eles iniciaram suas descobertas e consequente descrição dos elementos isótopos, utilizando o prefixo meta para a segunda variedade de um elemento químico.

A primeira observação de um isótopo foi do neônio, cuja espécie então conhecida tinha peso atômico 20 (com base em $\mathrm{H}=1$ ). Os ocultistas encontraram uma segunda variedade deste elemento, com peso atômico 22,33. Posteriormente foram analisados o argônio, criptônio e o xenônio e seus isótopos.

Este episódio merece um destaque, pois fez parte da história da descoberta dos isótopos, escrita pela ciência convencional. Jeff 
Hughes, professor da Universidade de Manchester nos traz um exemplo, dentre muitos, das estranhas rotas que muitas vezes a descoberta científica pode tomar. ${ }^{23}$

O início do século XX marcou a descoberta desse novo grupo de átomos, pelo uso dos "raios positivos", feixes de átomos ionizados - cátions - resultantes das descargas elétricas sobre vestígios de gases remanescentes nos tubos de raios catódicos. Os raios positivos eram também chamados de "raios canais". Fazendo uso desses raios, Joseph J. Thomson observou, em 1911, resultados que apontavam para a existência de um átomo de massa atômica 3. Ele batizou-o naquela oportunidade por $\mathrm{X}_{3}$ e passou a investigá-lo mais a fundo. Nesse período, Thomson recebeu em seu laboratório Francis William Aston (1877-1945), ex-aluno de John Poynting, da Universidade de Birmingham. Aston era exímio artesão do vidro e conhecedor de física. Ele aperfeiçoou os dispositivos de Thomson, em especial o equipamento de raios positivos. Com isso, observou as linhas oriundas da ionização de gases raros, espécies ainda pouco estudadas para a época, dada a dificuldade de seu isolamento. Além de observar a linha decorrente do neônio, cuja massa atômica conhecida era de 20,2, ele observou a presença de uma linha extra, correspondente a um átomo de massa 22. Imaginou Aston que se tratava de um novo elemento, e batizou-o de "metaneonio".

Em nota de rodapé de um artigo enviado à British Association em 1913, ele se refere à obra Occult Chemistry: a series of clairvoyant observations on the chemical elements, de Besant e Leadbeater. Vejamos o que diz a nota,

By theosophic methods unintelligible to the mere student of physics, [the authors] claimed to have determined the atomic weights of all the elements known, and several unknown at the time. Among the latter occurs one to which they ascribe an atomic weight of 22,33 $(H=1)$ and which they call "Meta Neon". As this name seems to suit as well as any other, what little we know of the properties of the new gas, I have used it in this paper (Hughes, 2003, p.32). ${ }^{23}$

Em carta endereçada aos editores da revista Nature, Aston faz referência a isótopos do cloro. O título da nota corrobora o empréstimo do termo 'meta' junto aos químicos ocultistas: The separation of the element chlorine into normal chlorine and meta-chlorine, and the positive electron. ${ }^{24}$

Francis Aston recebeu o Prêmio Nobel de Química em 1922, pela descoberta dos isótopos de um grande número de elementos não-radioativos. Em seu discurso de premiação e na sua célebre obra Isotopes, Aston reconstruiu a história de seus trabalhos que conduziram à descoberta do neônio-22 e outros isótopos. A história foi contada de modo linear. O termo "metaneonio" foi atribuído a Crookes e todas as referências aos químicos ocultistas bem como sua proposta de um novo átomo foram eliminadas. A história assim reconstruída ganhou rápida aceitação na comunidade científica.

A nova narrativa desconectou a teoria nuclear isotópica de algumas das ideias que, para seus idealizadores, pareciam algo embaraçosas. Da forma como foi (e ainda é) contada, a história parece mostrar que tal teoria sempre pareceu óbvia e plausível para dar conta da estrutura atômica e elimina uma das fontes originais e imaginativas de elaboração e consolidação de conhecimento científico.

Nas últimas décadas do século XX o físico teórico Stephen Philips resgatou o Occult Chemistry. Em sua obra Extrasensory perception of subatomic particles, ${ }^{25}$ ele aponta notáveis similaridades entre os trabalhos de Besant e Leadbeater sobre a estrutura atômica e os resultados obtidos pela física de partículas. O trabalho de Philips sustenta as conexões entre a ciência e a teosofia feita noventa anos antes por Aston e mostra que a cultura científica é tão rica e variada quanto há um século atrás. Cabe, nesse ponto, uma pergunta que ainda não foi feita: seria o occultum o elemento correspondente ao isótopo de massa 3 do hidrogênio?

\section{A ARQUITETURA DOS ÁTOMOS}

Examinada a estrutura última da matéria, os químicos ocultistas passaram a investigar de que forma os anu se distribuíam no espaço para compor os átomos. Observando os elementos químicos em seus estados etéricos intermediários, ou seja, os estados proto, hiper e meta-elementar (E4, E3, E2, conforme Figura 2) eles notaram que os апи estavam distribuídos dentro de estruturas e formas geométricas peculiares a cada elemento. Influenciados pela tradição teosófica, prontamente associaram as formas geométricas aos sólidos platônicos. A partir disso, elaboraram uma classificação baseada na semelhança de formas e propriedades, uma das quais sua valência. Os átomos foram então classificados em seis grupos, conforme passamos a descrever.

Os Halteres (dumb-bell) são estruturas características dos elementos monovalentes, reconhecidos por possuírem em alguma parte de sua estrutura duas projeção com 12 funis que circundam um ovoide central e que estão ligadas por uma haste, uma na parte superior e outra na parte inferior. O sódio (Figura 4) é elemento representativo dessa categoria.
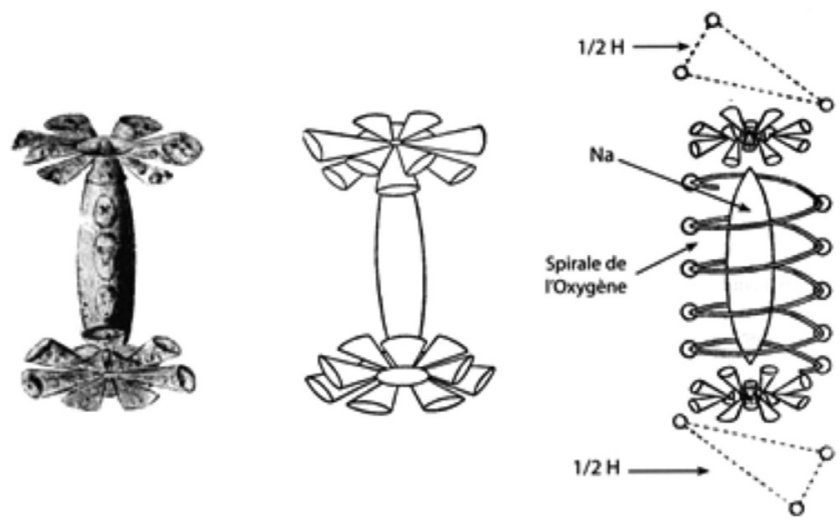

Figura 4. Estrutura do sódio (esquerda e centro) e identificação deste elemento na estrutura de um composto, o hidróxido de sódio (direita). Notar a espiral de oxigênio. Besant \& Leadbeater, La Chimie Occulte

Para o sódio a contagem do número de "anu" procede, segundo os QO, da seguinte forma:

Funis parte superior: 16 "anu" cada funil $\ldots \ldots . . .=192 \mathrm{anu}$

Globo central............................................. $=10 \mathrm{anu}$

Haste que liga os funis .................................. $=14 \mathrm{anu}$

Funis parte inferior + ovoide central .............. $=202 \mathrm{anu}$

Total ..................................................... $=418 \mathrm{anu}$

Peso atômico 418/18 ....................................... = 23,22

Peso atômico aceito para a época.................... $=22,99$

O Tetraedro é a forma geométrica típica dos elementos bivalentes. Eles possuem corpúsculos ovoides dentro de funis que estão sobre a face de um tetraedro. O berílio (Figura 5) é elemento típico desse grupo.

O Cubo caracteriza os elementos trivalentes. Eles possuem corpúsculos ovoides dentro de funis que estão alojados nas faces do cubo. O principal exemplo deste grupo é o boro (Figura 5). A figura mostra ainda a dissociação deste elemento em seus estados etéricos intermediários.

O Octaedro é típico dos elementos tetravalentes. Neste grupo 

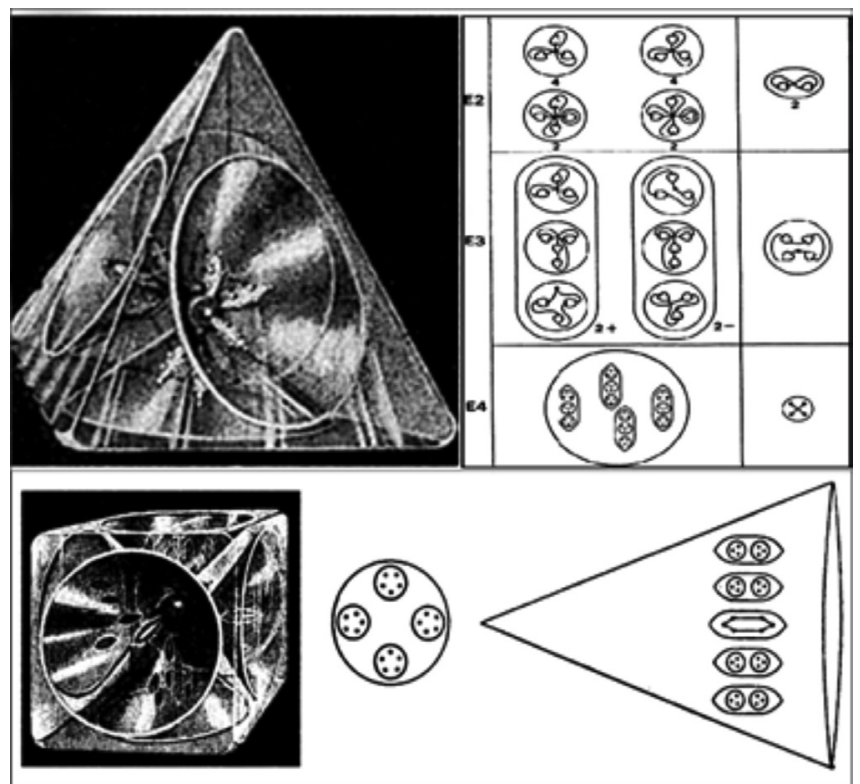

Figura 5. Acima: na parte esquerda é mostrado um átomo inteiro do berílio, e a direita suas subestruturas nos estados etéricos irtermediários E4, E3, E2 (Besant \& Leadbeater, La Chimie Occulte). Abaixo: Na parte esquerda é mostrado um átomo inteiro de Boro, e a direita, suas duas subestruturas (Besant \& Leadbeater, La Chimie Occulte)

também aparecem funis, oito no total, que se dispõem sobre as faces de um octaedro. O principal exemplo é o carbono (Figura 6). A figura ainda apresenta suas duas subestruturas num estado etérico intermediário, e ainda um exemplo de como este elemento é identificado na visualização de um composto, no caso, o monóxido de carbono.
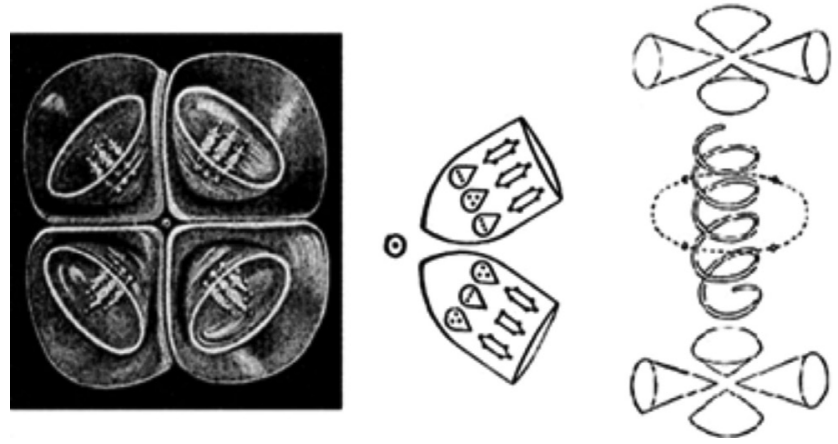

Figura 6. À esquerda é mostrado um átomo de carbono, ao centro suas duas subestruturas e a direita a imagem do monóxido de carbono (Besant \& Leadbeater, La Chimie Occulte)

Um conjunto de Barras caracteriza um grupo de elementos que receberam o nome de "interperiódicos". Nos elementos deste grupo aparecem 14 barras (hastes) entrecruzadas radialmente em um centro comum. Diferem uns dos outros pelo peso de cada barra. O ferro (Figura 7) é representante típico desse grupo. A figura ainda apresenta sua subestrutura num estado etérico intermediário.

A forma geométrica típica de Estrela é a principal característica de um grupo de elementos que possuem em sua estrutura uma estrela plana com cinco tetraedros entrelaçados no centro. O grupo engloba alguns elementos divalentes, trivalentes e tetravalentes que possuem números diferentes de funis em suas substruturas. Os gases nobres fazem parte desse grupo e o neônio (Figura 7) é um de seus representantes. Aparece também na figura a subestrutura de seu isótopo, o meta-neônio.
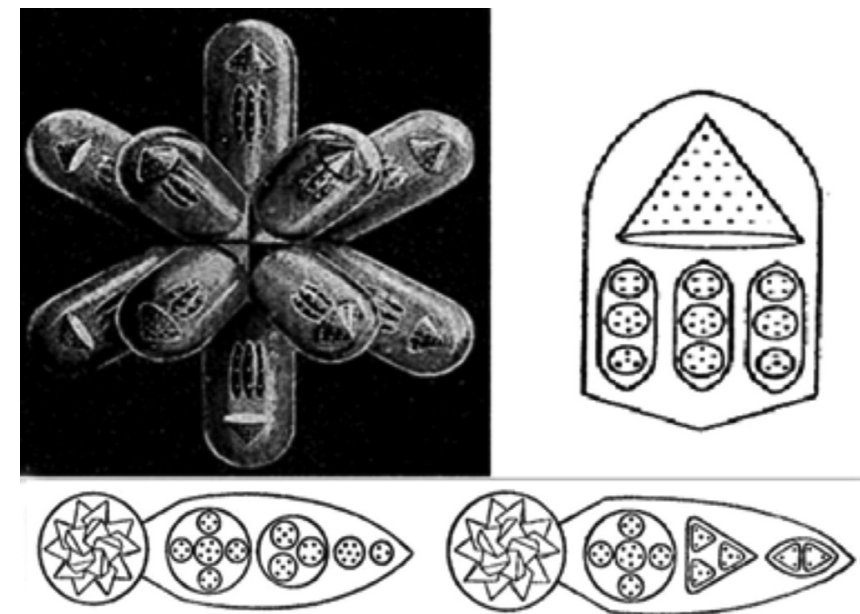

Figura 7. O átomo de ferro e suas subestruturas (acima) e os átomos de neônio (abaixo à esquerda) e meta-neônio (abaixo à direita)

Os ocultistas prosseguiam com suas pesquisas e, em 1919, foram elucidadas as estruturas de alguns compostos de estrutura não muito complexas, como o sal e a água. Neste mesmo ano foi publicada uma segunda edição do Occult Chemistry, que não continha nenhuma novidade a não ser uma introdução escrita por M. A. P Sinnet. Em 1922 o trabalho foi revisto por Leadbeater e as descrições de muitos compostos foram então publicados pela primeira vez em março, abril e agosto de $1924 .{ }^{26}$ Diversas outras estruturas de compostos foram publicadas em março, abril, agosto, setembro e outubro de 1925 e julho de 1926. Certos compostos de carbono com suas cadeias alifáticas e aromáticas estavam entre os materiais examinados. Em setembro de 1925 apareceu, no jornal The Theosophist, uma descrição da estrutura do diamante. Em 1932 e 1933 Leadbeater esteve em Adyar, na Índia, e publicou a descrição de novos elementos identificados, dentre eles, os de pesos atômicos $85,87,91$.

Os pesos atômicos de todos os elementos apresentados pelos investigadores teosóficos concordaram com bastante precisão com os pesos atômicos determinados pelas publicações científicas da época. Os mesmos afirmam que utilizavam, para verificar seus resultados, estudos e publicações do físico inglês Willian Crookes, colega dos investigadores, que foi membro da Sociedade Teosófica por muitos anos, e também muito conhecido da comunidade por seus estudos dos fenômenos espiritualistas. ${ }^{27}$

Todas essas investigações foram incorporadas na terceira edição do Occult Chemistry, com todos os textos revistos e apoiados com esquemas de desenhos a fim de ilustrar mais claramente os modelos examinados pelos ocultistas. Nesta edição, o texto é apresentado em três partes, a primeira constituindo uma introdução geral, a segunda, um estudo geral de todos os elementos, e a terceira contendo todas as informações disponíveis sobre combinação de elementos e compostos.

Podemos verificar também em suas publicações, que os químicos ocultistas tentaram explicar a estrutura da matéria possivelmente por estarem influenciados pelos debates em voga da ciência 'oficial', e retiraram das publicações científicas da época as bases teóricas para o seu trabalho. É possível, por exemplo, dizer que foram influenciados pela teoria atômica de John Dalton (1766-1844) e suas hipóteses, que foram amplamente discutidas durante todo o século XIX. Segundo Oki, ${ }^{28}$ em novembro de 1805 , Dalton já apresentara à comunidade científica uma tabela de pesos atômicos (massas atômicas relativas), e havia utilizado o termo "partícula última" para se referir tanto a átomos quanto às moléculas, bem como adotara o hidrogênio como elemento de referência para determinar pesos atômicos, ao qual atribui peso unitário. 


\section{CONSIDERAÇÕES FINAIS}

Apesar das impressionantes ideias e predições de elementos químicos, em especial os não conhecidos para a época, o método de investigação utilizado pelos químicos ocultistas certamente não se enquadrou na tradição empirista, fortemente aceita no século XIX, que valorizava a verificação através da experiência e questionava com rigor o estudo de entidades não visíveis e hipotéticas, como no caso dos átomos. Em razão disso, Annie Besant e seu grupo receberam duras críticas e seus trabalhos foram rejeitados pela comunidade científica. ${ }^{13}$

Sem entrar no mérito da clarividência como forma de conhecimento de mundo, claro está que o trabalho dos Ocultistas foi rejeitado por conta de sua metodologia não fazer parte do paradigma científico vigente. É provável que suas ideias tenham sido enquadradas na categoria do misticismo, charlatanismo ou pura especulação ingênua, fazendo parte da história das chamadas pseudociências.

O trabalho de Besant e dos químicos ocultistas, com suas representações e descrições fantásticas não deixam de impressionar: de uma parte, por sua beleza e excentricidade e, por outra, pela sua ingenuidade em buscar na teosofia uma explicação para os problemas emergentes da química e da física daquele período.

Ainda que as ideias do grupo fossem e ainda sejam enquadradas na categoria de 'pseudociência' ou ciência marginal, sua proposta pode tornar-se um episódio relevante para a reflexão de aspectos relativos à natureza da ciência. O que ocorre, na maioria das vezes, é que a História da Química é escrita e reescrita, e dela são removidos fatos que pareçam inconvenientes, idiossincrasias e ideias prematuras, deixando somente um caminho racionalizado e moldado como parte de uma sequência linear de "descobertas" científicas. O resultado disso é que, não somente a história é distorcida, mas também remete os estudantes a uma visão simplista de como a ciência progride, como se ela o fizesse apenas de modo racional, excluindo a riqueza da atividade científica, do papel da imaginação e a originalidade dos que com ela se envolvem.

Seria temerário negar completamente que o trabalho dos Químicos Ocultos não tenha trazido qualquer contribuição ao desenvolvimento da Teoria Atômica. Esse desenvolvimento se fez por ideias, por erros e acertos, e negar algumas delas seria desprezar pensadores que, à sua maneira, contribuíram com o trabalho dos cientistas atômicos.

A apresentação que aqui fizemos, dos Químicos Ocultistas e sua relação com os debates sobre a estrutura do átomo que ocorreram ao final do século XIX pode tornar-se material rico para a abordagem explícita e reflexiva de aspectos relativos à natureza da ciência em sala de aula. Isto porque, por meio do estudo de discussões científicas e pseudocientíficas como as apresentadas neste artigo, alunos e professores de Química podem compreender melhor a construção da ciência oficial e de seus episódios de ciência "não-oficial", mostrando que, ao final, a busca do conhecimento científico é uma requintada atividade social. ${ }^{29}$

Acreditamos, assim como Allchin, ${ }^{30}$ que situações como a aqui relatada, de discordância com a ciência oficial podem, paradoxalmente, oferecer uma oportunidade ideal para se ensinar a natureza dessa empreitada humana, tornando-se um importante veículo para corrigir suas falsas impressões.

Foi assim que, neste trabalho procuramos fornecer, por meio de um episódio esquecido e que podemos classificar como "oculto" pela ciência dominante, uma oportunidade para se discutir como a História da Química é formada pela exploração de fatos, onde se entrecruzam diferentes culturas, processos e interpretações de mundo.

\section{MATERIAL SUPLEMENTAR}

Este trabalho apresenta material suplementar, disponível gratuitamente, no qual são mostradas outras estruturas de átomos e moléculas, conforme registrado pelos químicos ocultistas. O material pode ser encontrado em http://quimicanova.sbq.org.br, na forma de arquivo PDF, com livre acesso.

\section{AGRADECIMENTOS}

A autora L. Forostecki agradece o apoio recebido na forma de bolsa, da Coordenação de Aperfeiçoamento de Pessoal de Nível Superior (CAPES) e da Fundação Araucária de Apoio ao Desenvolvimento Científico e Tecnológico do Estado do Paraná, que possibilitou o desenvolvimento desta pesquisa.

\section{REFERÊNCIAS}

1. Bensaude-Vincent, B.; Stengers, I.; História da Química, Instituto Piaget: Lisboa, 1992, 162.

2. Newton I., Optiks, in: Boorse, H. A.; Motz, L.; Weaver, J. H.; The Atomic Scientists: a biographical history; Wiley: New York, 1989, 28.

3. Porto, P. A.; Quim. Nova 1997, 20, 335.

4. Boorse, H. A.; Motz, L.; Weaver, J. H.; The Atomic Scientists: a biographical history; Wiley: New York, 1989, 31.

5. Gay-Lussac; Arago; Chevreul; Savary; Dumas; Pelouze; Boussingault; Regnault, Ann. Chim. Phys., série 3, tomo 1, Paris, 1841, 24.

6. Crookes, W.; Genèse des Éléments: mémoire lu le 18 février 1887 a L'Instituition Royale, Gauthier: Paris, 1887.

7. Bensaude-Vincent; B.; Stengers, I.; op. cit., 170.

8. Xavier, A.M.; Lima, A.G.; Vigna, C.R.M.; Verbi, F. M.; Bortoleto, G. G.; Goraieb, K.; Collins, C. H.; Bueno, M.I.M.S.; Quim. Nova 2007, 30, 83.

9. Santin Filho, O.; Quim. Nova 1995, 18, 574.

10. Castilho, C. M. C.; Rev. Bras. Ensino Fís. 2003, 25, 364.

11. Ibid., 365 .

12. Butler, A.; Chem. Br. 1991, 40.

13. http://www.chem.yale.edu/ chem $125 / 125 /$ history $99 / 8$ Occult/ OccultAtoms.html, acessada em Julho 2013.

14. Besant, A.; Autobiografia, Pensamento: São Paulo, 1948.

15. Butler, A.; op. cit., p. 41.

16. Butler, A.; op. cit., p. 42.

17. Morrison, M.; Canadian Art Review 2009, 1, 86.

18. Morrison, M.; Modern Alchemy, Occultism and the Emerging of Atomic Theory, Oxford University Press: New York, 2007, p. 68.

19. Leadbeater, C. W.; Besant, A.; Occult Chemistry, a series of clairvoyant Observations on the Chemical Elements, Dodo Press: Slough, 1919.

20. Leadbeater, C. W.; Besant, A.; Occult Chemistry: Investigations by Clairvoyant Magnification into the Structure of the Atoms of the Periodic Table and of Some Compounds, Kessinger Publishing: Whitefish, 1950.

21. Besant, A.; Leadbeater, C. W.; La Chimie Occulte. Série d'observations faites sur les éléments chimiques au moyen de la clairvoyance, $2^{\text {éme }} \mathrm{ed}$., Éditions Adyar: Paris, 2004.

22. Fretter, W.B.; Annu. Rev. Nucl. Sci. 1995, 5, 145.

23. Hughes, J.; Phys. World 2003, 33.

24. Aston, F. W; Nature 1920, 105, 231.

25. Phillips, S. M.; Journal of Scientific Explanation 1995, 9, 489.

26. Uma versão eletrônica dessa obra está disponível gratuitamente em http://www.bookdepository.co.uk/free, acessada em Julho 2013.

27. Ferreira, J. M. H.; Martins, R. A.; As investigações de William Crookes sobre fenômenos espiritualistas com médiuns e suas pesquisas sobre o efeito radiométrico na década de 1870, in: O Laboratório, a Oficina e o Ateliê: a Arte de Fazer o Artificial, Alfonso-Goldfarb, A. M.; Beltran, M. H. R. orgs.; EDUC/FAPESP: São Paulo, 2002, 169.

28. Oki, M. C. M.; Quim. Nova 2009, 32, 1073.

29. Ferreira, J. M. H.; Resumos do VII ENPEC - Encontro Nacional de Pesquisa em Educação em Ciências, Florianópolis, Brasil, 2009.

30. Allchin, D.; Science and Education 2004, 13, 179. 


\section{OS QUÍMICOS OCULTOS E SUA EXTRAORDINÁRIA JORNADA AO MUNDO DOS ÁTOMOS}

\section{Lediany Forostecki e Ourides Santin Filho*}

Departamento de Química, Centro de Ciências Exatas, Universidade Estadual de Maringá, Av. Colombo, 5790, 87020-900 Maringá - PR, Brasil

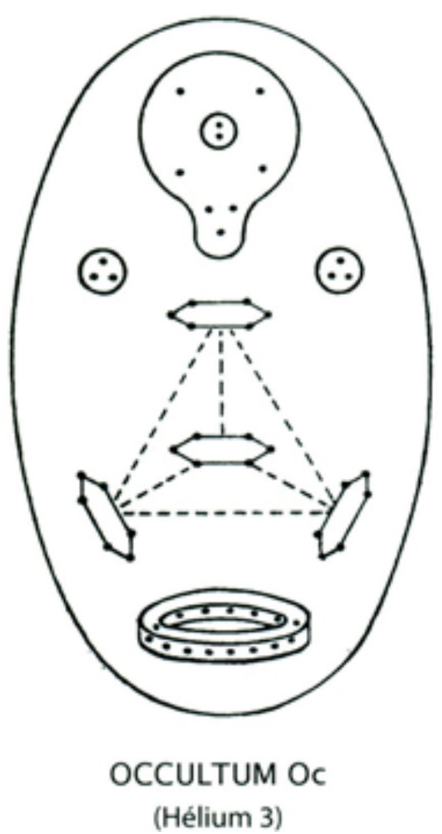

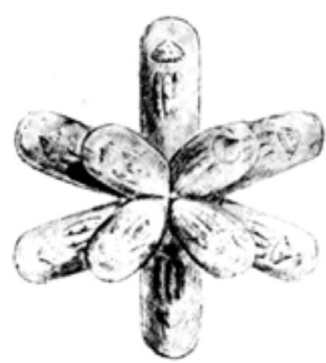

1 FER, COBALT, NICKEL

Figura 1S. Um átomo de Occultum

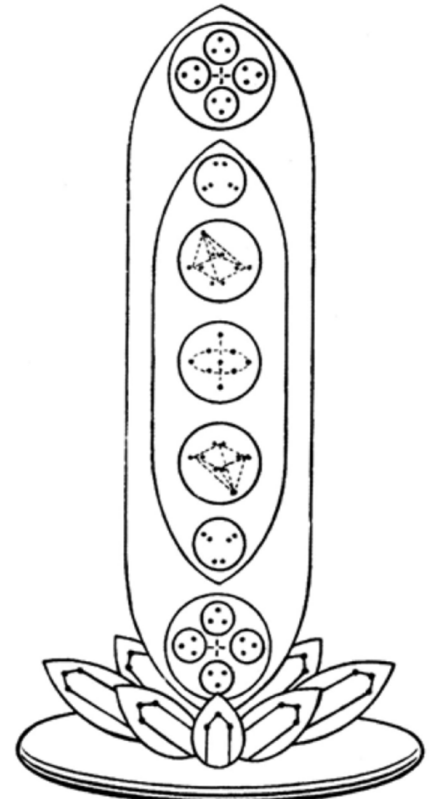

Figura 2S. Um átomo de Lítio, na concepção dos Químicos Ocultos
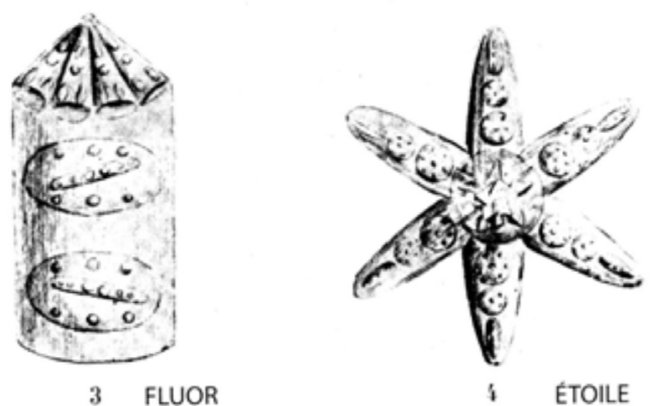

i ÉTOILE

3 FLUOR

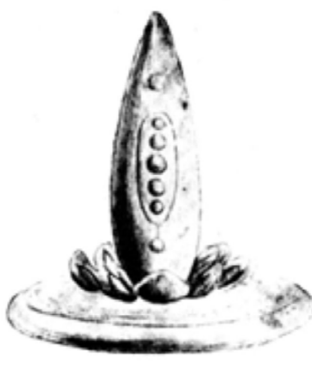

$2 \quad$ LITHIUM
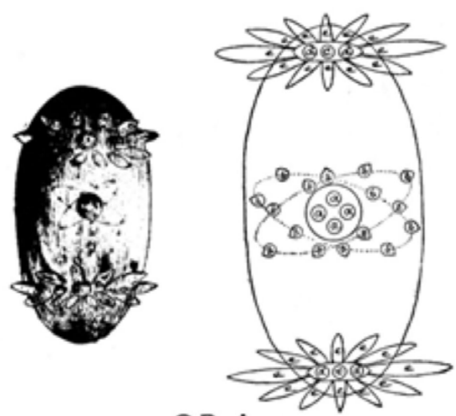

$\mathrm{OR} \mathrm{Au}$

Figura 3S. Representações tridimensionais e esquemáticas de diversos átomos 
S2

Forostecki e Santin Filho

Quim. Nova

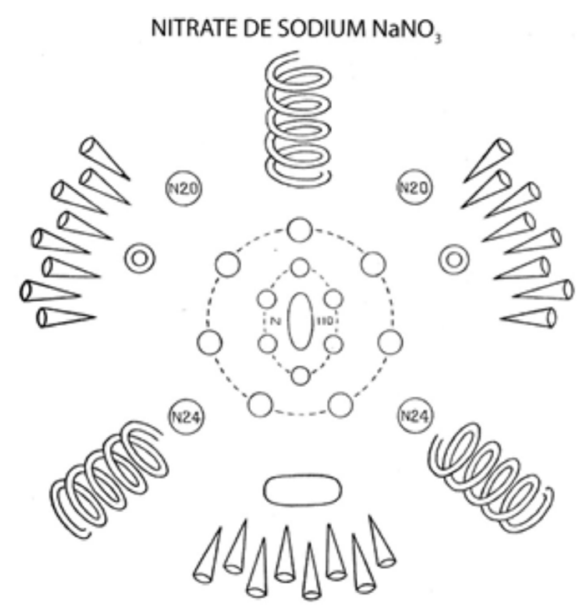

Figura 4S. O nitrato de sódio, segundo os Químicos Ocultos

ACIDE SULFURIQUE $\mathrm{H}_{2} \mathrm{SO}_{4}$

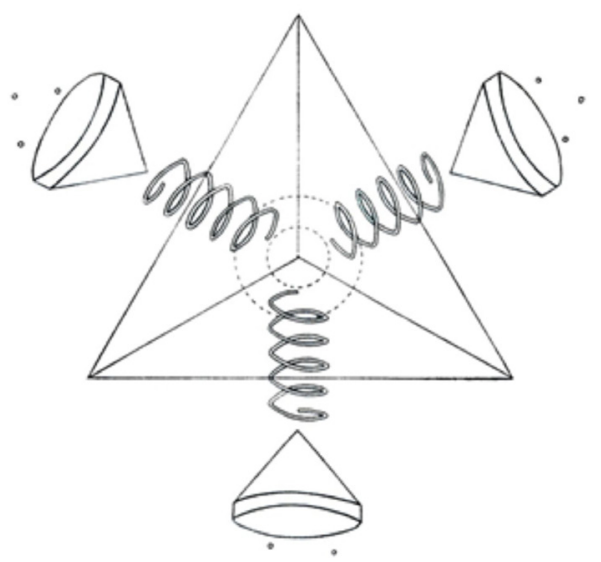

Figura 5S. O ácido sulfúrico, segundo os Químicos Ocultos
HYDROQUINONE $\mathrm{C}_{6} \mathrm{H}_{4}(\mathrm{OH})_{2}$ \&10000)\%
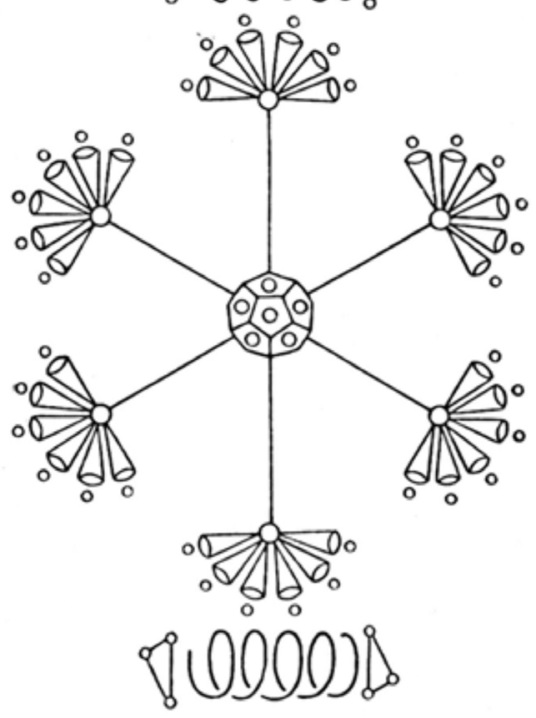

Figura 6S. A hidroquinona, segundo os Químicos Ocultos 